\title{
Utilização de argilas esmectíticas do nordeste do Brasil para preparação de um adsorvente organofílico
}

\section{(Utilization of smectit clays from the northeast of Brazil for preparing an organophilic adsorber)}

\author{
J.V.F. L. Cavalcanti ${ }^{1}$, M. da Motta ${ }^{I}$, C.A.M.Abreu ${ }^{I}$, O. S. Baraúna ${ }^{2}$, L. A. P. Portela ${ }^{2}$ \\ ${ }^{I}$ Departamento de Engenharia Química, Universidade Federal de Pernambuco, R. Prof. Arthur de Sá s/n, \\ Cidade Universitária, Recife, PE 50740-521 \\ ${ }^{2}$ Associação Instituto de Tecnologia de Pernambuco - ITEP, Av. Prof. Luiz Freire 700 \\ Cidade Universitária, Recife, PE 50740-570 \\ jorgevcavalcanti@ig.com.br,mottas@ufpe.br
}

\begin{abstract}
Resumo
O principal objetivo foi a preparação e a utilização de uma argila organofílica com capacidade de promover a separação do composto fenol, encontrado em larga escala nos efluentes aquosos de indústrias petroquímicas. O trabalho consistiu no preparo de um material adsorvente, partindo de cinco tipos diferentes argilas retiradas de bacias localizadas na região nordeste do Brasil: Verde Lodo, Bofe e Chocolate, retiradas do município de Campina Grande, Boa Vista, PB; e Lagoa de Dentro e S. Jorge, do Pólo Gesseiro do Araripe, PE. As argilas in natura foram tratadas com uma solução de carbonato de sódio visando a troca dos policátions existentes em suas regiões intercamadas pelo cátion sódio, em um reator de bancada, com diferentes concentrações, tempo de contato e temperatura, de acordo com um planejamento experimental $2^{3}$. Como resposta ao tratamento com carbonato de sódio, fez-se a leitura das viscosidades plásticas (cP ou mPa.s) das suspensões aquosas desse material com 4,86\% em massa. Os resultados mostraram que a argila Chocolate, na melhor condição do planejamento experimental, atingiu uma viscosidade plástica de $4 \mathrm{mPa} . \mathrm{s}$, sendo, portanto, escolhida como material adsorvente. Em seguida, este material foi submetido a um tratamento com sal quaternário de amônio em duas concentrações diferentes visando a troca catiônica de sódio por cátions amônio quaternário. Após o preparo do material adsorvente, foram realizados ensaios adsortivos de equilíbrio, sendo verificado o efeito da concentração do sal quaternário de amônio no processo adsortivo de remoção do fenol. A eficiência adsortiva, para uma relação de massa $1 \mathrm{~g}$ de argila organofílica e volume de solução fenólica igual a $100 \mathrm{~mL}$, com concentrações iniciais entre 20 e $110 \mathrm{mg}$. $\mathrm{L}^{-1}$, foi de aproximadamente $70 \%$. Palavras-chave: argila organofílica, adsorção, fenol.
\end{abstract}

\begin{abstract}
The goal of this research was the preparation and use of organophilic clay capable of promoting the separation of phenol, found in large scale in the aqueous effluent of petrochemical industries. The studies consisted of preparing adsorbent material, based on five different types of clay taken from ponds located in the Northeast of Brazil, which are: Verde Lodo, Bofe and Chocolate, from Campina Grande, Boa Vista, PB, Brazil, and Lagoa de Dentro and S. Jorge, from Araripe's pole of plaster in PE, Brazil. In experimental scale the clays in natura were treated with a solution of sodium carbonate, to the exchange of poly-cations exist in their interlayer regions by the sodium cation, used different concentrations, temperature and time of contact, according to a experimental design $2^{3}$. In response to treatment with sodium carbonate, was reading the plastic viscosity (cP or $\left.m P a . s\right)$ of aqueous suspensions of this material with $4.86 \%$ by weight. The result showed that the Chocolate clay, in the best condition of the experimental design, has a plastic viscosity equal to $4 \mathrm{mPa}$.s and therefore was chosen as adsorbent material to continue the study. The Chocolate clay was subjected to a treatment with quaternary ammonium salt, in two different concentrations, to cation exchange of sodium by quaternary ammonium cations. After preparing the adsorbent material, were tested adsorptive equilibrium was verified the effect of the concentration of the quaternary ammonium salt in the adsorptive process to removal of phenol. The adsorptive efficiency for a ratio (wt/vv) of $1 \mathrm{~g}$ of organophilic clay in $100 \mathrm{~mL}$ of phenolic solution, with initial concentrations between 20 and $110 \mathrm{mg} . \mathrm{L}^{-1}$, was approximately $70 \%$.
\end{abstract}

Keywords: organophilic clays, adsorption, phenol.

\section{INTRODUÇÃO}

O uso crescente de compostos e produtos originados do petróleo tem acarretado em problemas sérios à saúde humana e ao meio ambiente. A argila hidrofílica montmorilonita é um adsorvente ineficaz para compostos orgânicos aromáticos que se movem freqüentemente dos locais contaminados. Entretanto, pode-se realçar a eficiência adsortiva desta argila pela substituição dos cátions inorgânicos presentes em sua estrutura original pelos surfactantes catiônicos maiores, 
como os cátions amônio quaternários, criando adsorventes que retardam a migração de tais poluentes [1]. A definição clássica designa argila como um material natural, terroso, de granulação fina, que quando umedecido com água apresenta plasticidade [2,3]. Os minerais constituintes das argilas são os argilominerais, sendo os mesmos silicatos hidratados que possuem estrutura em camadas constituídas por folhas contínuas formadas por tetraedros de silício (ou alumínio) e oxigênio, e folhas formadas por octaedros de alumínio (magnésio ou ferro), oxigênio e hidroxilas. A nomenclatura para os tipos de camadas é uma simples expressão da razão entre as folhas tetraédricas e as folhas octaédricas. Assim sendo, um argilomineral com camada 1:1 tem uma folha tetraédrica e uma folha octaédrica, enquanto que um
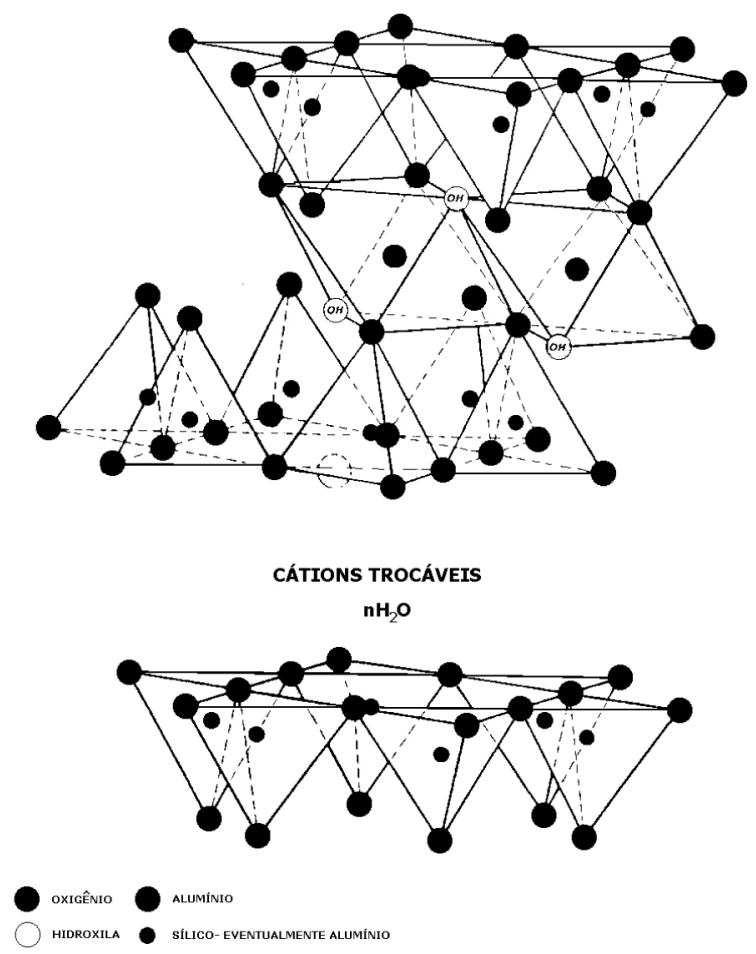

Figura 1: Estrutura cristalina das argilas esmectíticas.

[Figure 1: crystal structure of smectite clays.] argilomineral do tipo 2:1 apresenta duas folhas tetraédricas e uma folha octaédrica interna. A distância interlamelar ou distância interplanar basal também é utilizada para classificar as diferentes argilas existentes [3, 4]. A Fig. 1 ilustra a estrutura cristalina das argilas esmectíticas.

$\mathrm{O}$ tratamento de argilas esmectíticas com sais quaternários de amônio em concentrações superiores a sua capacidade de troca de cátions (CTC) corrobora com o aumento da capacidade adsortiva devido à fixação de íons amônio quaternário nas regiões intercamadas e na superfície externa dos argilominerais, bem como aumenta gradativamente a distância interplanar basal [5]. Um trabalho acadêmico desenvolveu um esquema para obtenção da argila organofílica após tratamento com sódio e sal quaternário de amônio, ilustrado na Fig. 2. Este grupo de pesquisa baseouse na substituição dos cátions inorgânicos pelo cátion sódio e em seguida pelo cátion amônio quaternário nas regiões intercamadas [6].

Ao se entender o desenvolvimento compatível com a preservação dos recursos naturais, novas técnicas de tratamento de efluentes se fazem necessárias, a fim de que seja possível aliar baixos custos à eficiência da preservação ambiental e da saúde pública. As argilas apresentam alta viabilidade técnico-econômica decorrente do seu potencial de adsorção, que associado à sua disponibilidade abundante as tornam adsorventes de baixo custo. A argila montmorilonita, do grupo das esmectitas, é em relação ao carvão ativado bem mais acessível [7].

Água misturada com derivados de petróleo é produzida em grandes volumes em muitos processos industriais de produção desses derivados e de refino do óleo. Esta mistura deve ser tratada para separar os derivados de petróleo da água antes que a mesma possa retornar ao meio ambiente ou mesmo ser reutilizada no processo. Geralmente são instalados equipamentos de separação como coalescedores, sedimentadores por gravidade, flotadores com ar dissolvido dentre outros, visando reduzir as concentrações dos derivados de petróleo nos efluentes. Os tratamentos com os processos convencionais quando não são economicamente viáveis não apresentam eficiência adequada de separação

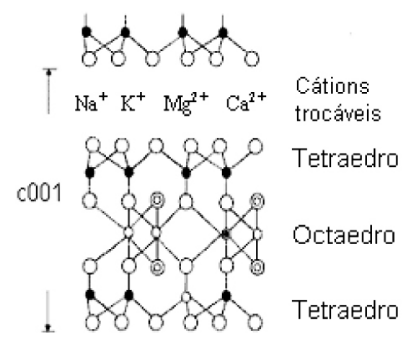

(a)

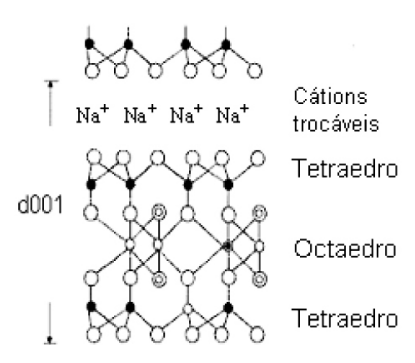

(b)

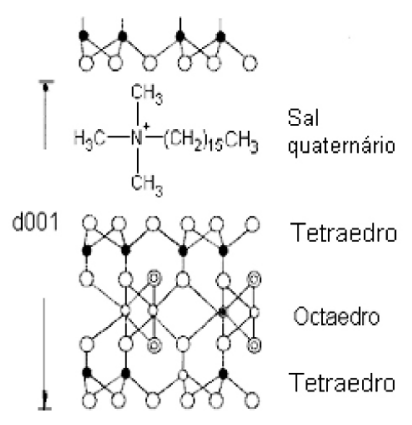

(c)

Figura 2: Esquema geral de obtenção da argila organofílica: representação da estrutura da argila in natura (a); da argila após tratamento com sódio (b); da argila após tratamento com sal quaternário (c).

[Figure 2: Schematic of overall achievement of organophilic clays: representation of the structure of in natura clay (a), the clay after treatment with sodium (b), after treatment with quaternary salt $(c)$. 
ou produzem grandes quantidades de lama que necessitam também de tratamento [8].

O fenol aparece nos efluentes de uma refinaria de petróleo oriundo das etapas de craqueamento catalítico, produção de lubrificantes e solventes e nas águas de lavagem da gasolina; a concentração média deste aromático nos efluentes foi 154 mg.L. $\mathrm{L}^{-1}$ [9]. A faixa de concentração dos efluentes fenólicos de uma refinaria está entre $0,9 \mathrm{mg} . \mathrm{L}^{-1}$ e $60 \mathrm{mg} . \mathrm{L}^{-1}$ [10].

No Brasil, o Conselho Nacional de Meio Ambiente (CONAMA), através da resolução 357/2005, estabelece parâmetros orgânicos e inorgânicos como padrões de lançamento de efluentes de qualquer fonte poluidora. A concentração máxima de fenóis totais, em efluentes, não deve exceder $0,5 \mathrm{mg} \cdot \mathrm{L}^{-1}$ [11].

A presença de grupos hidroxilas confere aos fenóis a capacidade de formar ligações de hidrogênio, o que dá aos mesmos pontos de ebulição acima de compostos orgânicos de massas moleculares próximas. O fenol é um composto sólido de cor branca e aparência cristalina, de fórmula molecular $\mathrm{C}_{6} \mathrm{H}_{5} \mathrm{OH}$, massa molar 94,11 g.mol ${ }^{-1}$, densidade 1,07 g.mL $\mathrm{mL}^{-1}$, ponto de fusão $40,5^{\circ} \mathrm{C}$, ponto de ebulição 181,7 ${ }^{\circ} \mathrm{C}$ e solubilidade em água a $20^{\circ} \mathrm{C}$ igual a $8,3 \mathrm{~g}$ para $100 \mathrm{~g}$ de água. Apresenta momento dipolar igual a $1,7 \mathrm{D}$ e constante ácida $\left(\mathrm{p} k_{A}\right)$ 9,95. É uma molécula com diâmetro 0,62 nm, quando considerada esférica $[12,13]$.

Os resíduos líquidos gerados por refinarias possuem diferentes composições químicas incluindo óleos e graxas, fenóis, BTEX (benzeno, tolueno, etil-benzeno e xilenos), amônia, sólidos suspensos, cianetos, sulfitos, compostos nitrogenados e metais pesados, tais como ferro, níquel, cromo, cobre, molibdênio, selênio, vanádio, zinco e cádmio. Buscando-se avaliar e monitorar o impacto ambiental provocado pelo lançamento de efluentes nos corpos hídricos, testes de toxicidade são muito utilizados como indicadores destes danos causados ao ambiente aquático. Os testes realizados em peixes, invertebrados e algas revelaram que a maioria dos efluentes de refinaria é tóxico, provocando nestes organismos, não apenas efeitos letais, como também alterações quanto ao seu crescimento e reprodução [14]. Dentre os poluentes orgânicos presentes nos efluentes de refinarias de petróleo em concentrações mais elevadas se destaca o fenol, resíduo que é gerado principalmente no craqueamento catalítico e no fracionamento de óleo cru. Além dessas fontes alguns processos utilizam fenol como solvente, contribuindo para o aumento da concentração de resíduos fenólicos nesses efluentes. Nesta pesquisa, foi avaliado o impacto causado pelo lançamento de efluentes de uma refinaria em um corpo hídrico receptor localizado na Nigéria. Foi verificado que a quantidade de fenol no efluente tratado lançado no delta do rio receptor apresentou um teor de $1,84 \mathrm{mg} . \mathrm{L}^{-1}$, valor superior ao máximo permitido pela legislação nigeriana que estabelece $0,5 \mathrm{mg} \cdot \mathrm{L}^{-1}$. O fenol é um dos resíduos mais difíceis de ser removido, normalmente envolvendo processos com eficiência pouco satisfatória e custos operacionais elevados. Além disso, trata-se de uma substância altamente tóxica, que pode provocar mortandade de peixes e outros organismos aquáticos [15]. Um grupo de pesquisa utilizou um sistema combinado de adsorção e ultrafiltração de argila caulinita e montmorilonita, concluindo-se que a rejeição à remoção do fenol e do o-cresol estava relacionada com o aumento do $\mathrm{pH}$ do sistema. Esta mesma influência pôde ser observada em outros trabalhos científicos [16, 17]. A eficiência de adsorção do fenol utilizando diferentes tratamentos para ativação de uma argila bentonita sódica, tais como surfactante catiônico brometo de cetil-tri-metil-amônio (CTAB), alumínio como pilarizante, $\mathrm{CTAB}$ e alumínio combinados $(\mathrm{CTAB} / \mathrm{Al})$, ciclohexano, bentonita tratada termicamente a $850{ }^{\circ} \mathrm{C}$ durante $30 \mathrm{~min}$ (tratamento físico isento de agentes químicos) e bentonita in natura, tendo os resultados apontado para a argila bentonita $\mathrm{CTAB} / \mathrm{Al}$ como a mais eficiente e a in natura como a menos eficiente. O aumento da temperatura, utilizando 25,35 e 45 ${ }^{\circ} \mathrm{C}$, desfavorecia a eficiência adsortiva [18]. Foi verificada a influência da modificação das argilas bentonitas nas suas propriedades adsortivas, tratando-as com brometo de tetra-decil-tri-metil-amônio (TDTAB) e brometo de hexa-decil-tri-metil-amônio (HDTAB), com mudanças em $25 \%, 50 \%$ e $100 \%$ da capacidade de troca catiônica desse adsorvente. O tempo de equilíbrio foi de aproximadamente $7 \mathrm{~h}$ e resultados cinéticos indicaram a possível presença de regiões heterogêneas nas superfícies das argilas modificadas com $25 \%$ e $50 \%$ de sua capacidade de troca catiônica. As argilas modificadas com TDTAB e HDTAB, em 100\% da sua CTC, obtiveram os melhores resultados para as eficiências de remoção [19]. Avaliando parâmetros termodinâmicos referentes ao estudo da adsorção do p-cloro-fenol na argila montmorilonita TBAM, este material pode ser um bom adsorvente para este composto [20]. Foi observada a adsorção do composto fenol e dos isômeros 2, 3 e 4 cloro-fenol, em argilas esmectíticas tratadas com cloreto de tetra-metilamônio (TMA) e brometo de tetra-metil-fosfônio (TMP) [21]. Os experimentos foram realizados com $100 \mathrm{mg}$ de argila em soluções de adsorvato 0,02 a $0,15 \mathrm{mmol} 100 \mathrm{~mL}^{-1}$, em erlenmeyer de $250 \mathrm{~mL}$, a $20^{\circ} \mathrm{C}$. Constatou-se que a argila esmectita tratada com TMP foi melhor adsorvente que a mesma tratada com TMA [21]. Foram investigadas a adsorção e retenção de hidrocarbonetos presentes na gasolina pelas argilas bentonitas organofílicas modificadas por sais quaternários de amônio, tais como benzil-tri-etilamônio (BTEA) e hexa-decil-tri-metil-amônio (HDTMA); os resultados do equilíbrio adsortivo para o benzeno seguem o modelo de Langmuir, para o BTEA, com capacidade de troca de cátions de 40 a $120 \%$, apresentando uma redução na eficiência de adsorção mediante o aumento da CTC. Já para o HDTMA os resultados apontaram para uma isoterma numa região linear, com CTC de 25 a 100\%. Em ambos os casos os resultados para remoção e retenção de contaminantes foram satisfatórios, concluindo que tais materiais podem ser utilizados para conter vazamentos em tanques contendo hidrocarbonetos [22].

Tendo em vista a possibilidade da preparação de um material organofílico capaz de provocar a adsorção de fenol em solução aquosa, destacam-se como principais objetivos deste trabalho a preparação e caracterização do material 
adsorvente, sua utilização para adsorção do fenol e avaliação estatística do modelo matemático adequado ao processo.

\section{Equilíbrio adsortivo - Isoterma de Langmuir-Freundlich}

O equilíbrio adsortivo representa o estado de igualdade entre a taxa cinética adsortiva e dessortiva. Uma das equações clássicas representantes deste estado é a isoterma de Langmuir-Freundlich, equação A:

$$
\theta_{\mathrm{A}}=\frac{\mathrm{K}_{\mathrm{A}} \mathrm{C}_{\mathrm{A}}{ }^{\mathrm{n}}}{1+\mathrm{K}_{\mathrm{A}} \mathrm{C}_{\mathrm{A}}{ }^{\mathrm{n}}}
$$

$K_{A}$ representa a constante de equilíbrio adsortivo $\left(\mathrm{L} \cdot \mathrm{mg}^{-1}\right)$, $C_{A}$ a concentração de adsorvato na fase líquida $\left(\mathrm{mg} . \mathrm{L}^{-1}\right) \mathrm{e}$ $n$ a intensidade adsortiva. $\mathrm{O}$ valor de $n$ pode ser igual a 1 , descrevendo então a isoterma de Langmuir, que considera adsorção em monocamadas, ou pode ser diferente de 1 , considerando adsorção em multicamadas, previsto pela isoterma de Freundlich. Define-se o parâmetro $\theta_{A}$ como a fração dos sítios ocupados por adsorção do componente "A" em relação ao total de sítios ocupados na saturação, podendo-se representá-lo de acordo com a equação B:

$$
\theta_{\mathrm{A}}=\frac{\mathrm{Q}_{\mathrm{A}}}{\mathrm{Q}_{\mathrm{A}}^{\mathrm{SAT}}}
$$

sendo $Q_{A}$ a concentração de adsorvato na fase sólida $\left(\mathrm{mg} \cdot \mathrm{g}^{-1}\right) \mathrm{e}$ $Q_{A}^{S A T}$ um parâmetro constante que representa a concentração máxima de sítios disponíveis do material adsorvente por grama de sólido (grama de adsorvato na saturação por grama de sólido), também denominado de capacidade máxima adsortiva. Reescrevendo-se a equação A, em função da capacidade máxima adsortiva e da concentração do adsorvato na fase sólida, obtém-se a equação C:

$$
\frac{\mathrm{Q}_{\mathrm{A}}}{\mathrm{Q}_{\mathrm{A}}^{\mathrm{SAT}}}=\frac{\mathrm{K}_{\mathrm{A}} \mathrm{C}_{\mathrm{A}}{ }^{\mathrm{n}}}{1+\mathrm{K}_{\mathrm{A}} \mathrm{C}_{\mathrm{A}}{ }^{\mathrm{n}}}
$$

Reorganizando-se a equação $\mathrm{C}$ e ajustando-se um valor para $n$, pode-se obter uma curva linear, conforme expressa a equação D:

$$
\frac{1}{\mathrm{Q}_{\mathrm{A}}}=\frac{1}{\mathrm{~K}_{\mathrm{A}} \mathrm{Q}_{\mathrm{A}}^{\mathrm{SAT}}}\left(\frac{1}{\mathrm{C}_{\mathrm{A}}}\right)^{\mathrm{n}}+\frac{1}{\mathrm{Q}_{\mathrm{A}}^{\mathrm{SAT}}}
$$

Os parâmetros $K_{A}$ e $Q_{A}^{S A T}$ podem ser determinados pelos coeficientes angular e linear da reta formada. Os valores de $C_{A}$ são determinados experimentalmente, enquanto que os valores de $Q_{A}$ podem ser calculados através do balanço geral representado pela equação $\mathrm{E}$ :

$$
\mathrm{Q}_{\mathrm{A}}=\frac{\left(\mathrm{C}_{\mathrm{A} 0}-\mathrm{C}_{\mathrm{A}}\right) \mathrm{V}}{\mathrm{m}_{\mathrm{s}}}
$$

sendo $C_{A 0}\left(\mathrm{mg} \cdot \mathrm{L}^{-1}\right)$ a concentração inicial do adsorvato, $V$ (L) o volume da solução e $m_{s}(\mathrm{~g})$ a massa do adsorvente.

\section{Análise de variância - ANOVA}

A análise de variância (ANOVA) é o método mais usado para se avaliar numericamente a qualidade do ajuste de um modelo [23]. Esta análise estatística baseia-se na relação existente entre a soma quadrática devido à regressão e a soma quadrática em torno da média, expressa pela equação $\mathrm{F}$ :

$$
\mathrm{D}^{2}=\frac{\sum(\hat{\mathrm{a}}-\overline{\mathrm{a}})^{2}}{\sum(\mathrm{a}-\overline{\mathrm{a}})^{2}}
$$

sendo $\hat{a}$ os valores calculados pelo o modelo em relação ao ponto em questão, $a$ os valores determinados experimentalmente e $\bar{a}$ a média global. $D^{2}$ é chamado de coeficiente de determinação do modelo. $\mathrm{O}$ valor máximo de $D^{2}$ é 1 , e só ocorrerá se não houver resíduo nenhum e, portanto, toda a variação em torno da média for explicada pela regressão. Quanto mais próximo de 1 estiver o valor de $D^{2}$, melhor terá sido o ajuste do modelo às respostas

\begin{tabular}{|c|c|c|c|c|c|c|c|c|}
\hline \multirow{4}{*}{$\begin{array}{c}\text { FATORES } \\
\text { Temperatura }\left({ }^{\circ} \mathrm{C}\right) \\
\text { Tempo de contato }(\mathrm{h}) \\
\text { Concentração do } \mathrm{Na}^{+} \\
(\text {meq } / 100 \mathrm{~g} \text { de argila } \\
\left.\text { seca a } 300{ }^{\circ} \mathrm{C}\right)\end{array}$} & \multicolumn{8}{|c|}{ NÍVEIS DOS FATORES } \\
\hline & \multicolumn{4}{|c|}{$\mathrm{T}_{1}=45$} & \multicolumn{4}{|c|}{$\mathrm{T}_{2}=90$} \\
\hline & \multicolumn{2}{|c|}{$\mathrm{t}_{1}=3$} & \multicolumn{2}{|c|}{$\mathrm{t}_{2}=6$} & \multicolumn{2}{|c|}{$t_{1}=3$} & \multicolumn{2}{|c|}{$\mathrm{t}_{2}=6$} \\
\hline & $C_{1}=100$ & $\mathrm{C}_{2}=200$ & $C_{1}=100$ & $C_{2}=200$ & $C_{1}=100$ & $\mathrm{C}_{2}=200$ & $C_{1}=100$ & $C_{2}=200$ \\
\hline Experimento & $\mathrm{T}_{1} \mathrm{t}_{1} \mathrm{C}_{1}$ & $\mathrm{~T}_{1} \mathrm{t}_{1} \mathrm{C}_{2}$ & $\mathrm{~T}_{1} \mathrm{t}_{2} \mathrm{C}_{1}$ & $\mathrm{~T}_{1} \mathrm{t}_{2} \mathrm{C}_{2}$ & $\mathrm{~T}_{2} \mathrm{t}_{1} \mathrm{C}_{1}$ & $\mathrm{~T}_{2} \mathrm{t}_{1} \mathrm{C}_{2}$ & $\mathrm{~T}_{2} \mathrm{t}_{2} \mathrm{C}_{1}$ & $\mathrm{~T}_{2} \mathrm{t}_{2} \mathrm{C}_{2}$ \\
\hline Matriz de Planejamento & --- & --+ & -+- & -++ & +-- & +-+ & ++- & +++ \\
\hline
\end{tabular}
observadas [23].

Tabela I - Definição dos tratamentos com base na combinação de níveis dos fatores envolvidos no processo de troca iônica de uma amostra de argila com carbonato de sódio P.A.

[Table I - Definition of treatments based on the combination of levels and factors involved in the process of ions exchange by one sample of clay with sodium carbonate P.A.] 
Tabela II - Definição dos tratamentos com base na combinação de níveis dos fatores minimizados envolvidos no processo de troca iônica de uma amostra de argila com carbonato de sódio P.A.

[Table II - Definition of treatments based on the combination of reduced levels on the factors involved in the process of ions exchange by one sample of clay with sodium carbonate P.A.]

\begin{tabular}{ccc|cc|cc|cc}
\hline \multicolumn{10}{c}{ NÍVEIS DOS FATORES } \\
\hline $\begin{array}{c}\text { Temperatura }\left({ }^{\circ} \mathrm{C}\right) \\
\text { Tempo de contato }(\mathrm{h})\end{array}$ & \multicolumn{3}{c}{$\mathrm{t}_{0}=1,5$} & \multicolumn{2}{c}{$\mathrm{T}_{0}=25$} & $\mathrm{t}_{1}=3$ & $\mathrm{~T}_{1}=45$ \\
\hline $\begin{array}{c}\text { Concentração de } \mathrm{Na}^{+} \\
\text {(meq/100 g de argila } \\
\left.\text { seca a 300 }{ }^{\circ} \mathrm{C}\right)\end{array}$ & $\mathrm{C}_{0}=50$ & $\mathrm{C}_{1}=100$ & $\mathrm{C}_{0}=50$ & $\mathrm{C}_{1}=100$ & $\mathrm{C}_{0}=50$ & $\mathrm{C}_{1}=100$ & $\mathrm{C}_{0}=50$ & $\mathrm{C}_{1}=100$ \\
\hline $\begin{array}{c}\text { Experimento } \\
\text { Matriz de Planejamento }\end{array}$ & $\mathrm{T}_{0} \mathrm{t}_{0} \mathrm{C}_{0}$ & $\begin{array}{c}\mathrm{T}_{0} \mathrm{t}_{0} \mathrm{C}_{1} \\
---\end{array}$ & $\begin{array}{c}\mathrm{T}_{0} \mathrm{t}_{1} \mathrm{C}_{0} \\
-+\end{array}$ & $\begin{array}{c}\mathrm{T}_{0} \mathrm{t}_{1} \mathrm{C}_{1} \\
-++\end{array}$ & $\begin{array}{c}\mathrm{T}_{1} \mathrm{t}_{0} \mathrm{C}_{0} \\
+--\end{array}$ & $\begin{array}{c}\mathrm{T}_{1} \mathrm{t}_{0} \mathrm{C}_{1} \\
+-+\end{array}$ & $\begin{array}{c}\mathrm{T}_{1} \mathrm{t}_{1} \mathrm{C}_{0} \\
++-\end{array}$ & $\begin{array}{c}\mathrm{T}_{1} \mathrm{t}_{1} \mathrm{C}_{1} \\
+++\end{array}$ \\
\hline
\end{tabular}

Tabela III - Concentração do cátion amônio quaternário como fator de modificação das argilas sódica e in natura.

[Table III - Quaternary ammonium cation concentration as a factor of modifications of sodium clays and natural clays.]

\begin{tabular}{|c|c|c|c|}
\hline \multirow[b]{2}{*}{$\begin{array}{c}\text { FATOR DE } \\
\text { MODIFICAÇÃO }\end{array}$} & \multicolumn{3}{|c|}{ EXPERIMENTO } \\
\hline & $\begin{array}{c}\text { I } \\
\text { (Argila in } \\
\text { natura) }\end{array}$ & $\begin{array}{c}\text { II } \\
\text { (Argila } \\
\text { sódica) }\end{array}$ & $\begin{array}{c}\text { III } \\
\text { (Argila } \\
\text { sódica) }\end{array}$ \\
\hline $\begin{array}{l}\text { Concentração do } \\
\text { cátion amônio } \\
\text { quaternário }\end{array}$ & $\begin{array}{c}\text { Igual a } \\
100 \% \\
\text { da CTC } \\
\text { dessa } \\
\text { argila. }\end{array}$ & $\begin{array}{c}\text { Igual a } \\
100 \% \\
\text { da CTC } \\
\text { dessa } \\
\text { argila. }\end{array}$ & $\begin{array}{c}\text { Igual a } \\
150 \% \\
\text { da CTC } \\
\text { dessa } \\
\text { argila. }\end{array}$ \\
\hline
\end{tabular}

\section{EXPERIMENTAL}

Preparação e caracterização do material adsorvente: foram coletadas 5 amostras de argila in natura: Verde Lodo, Bofe e Chocolate, do Município de Campina Grande (Boa Vista), PB, e Lagoa de Dentro e São Jorge, da região Pólo Gesseiro do Araripe, PE. As argilas in natura foram tratadas com uma solução de carbonato de sódio, visando à troca dos poli cátions existentes em suas regiões intercamadas pelo cátion sódio, em um reator de bancada, com diferentes concentrações, tempo de contato e temperatura, de acordo com um planejamento experimental $2^{3}$, descrito de forma detalhada pela Tabela I.

Para conclusão deste estudo foi realizado também um experimento (com repetição) referente ao ponto médio dos fatores, os quais foram: $\mathrm{T}=67,5^{\circ} \mathrm{C}, \mathrm{t}=4,5 \mathrm{~h}$ e $\mathrm{C}=150$ meq. $100 \mathrm{~g}^{-1}$. A necessidade de confirmação das respostas induziu a uma ampliação dos estudos calcada na redefinição e minimização de níveis dos fatores. Dando seguimento a este raciocínio foram concebidos oito novos experimentos (também com repetição) resultantes da combinação dos níveis dos fatores temperatura $\left(25^{\circ} \mathrm{C}\right.$ e $\left.45^{\circ} \mathrm{C}\right)$, tempo $(1,5$ e $3 \mathrm{~h}$ ) e concentração de sódio (50 meq e $100 \mathrm{meq})$, na construção de um novo planejamento fatorial onde o ponto médio foi o representado pelo experimento $\mathrm{T}=35^{\circ} \mathrm{C}, \mathrm{t}=2$ h e 15 min e $\mathrm{C}=75$ meq. $100 \mathrm{~g}^{-1}$ de argila. A Tabela II mostra como foi realizado este novo planejamento.

Dentre os cinco tipos de argila in natura tratadas com o carbonato de sódio, seguindo os planejamentos representados pelas Tabelas I e II, a que revelou melhor propriedade tixotrópica, com viscosidade plástica igual a 4,0 mPa.s, foi denominada de argila sódica, sendo a mesma submetida a ensaios de ataque com sal quaternário de amônio, tanto na sua versão inicial in natura como na nova versão sódica. Para a produção da argila organofílica foram feitos 3 ensaios, baseados na capacidade de troca catiônica

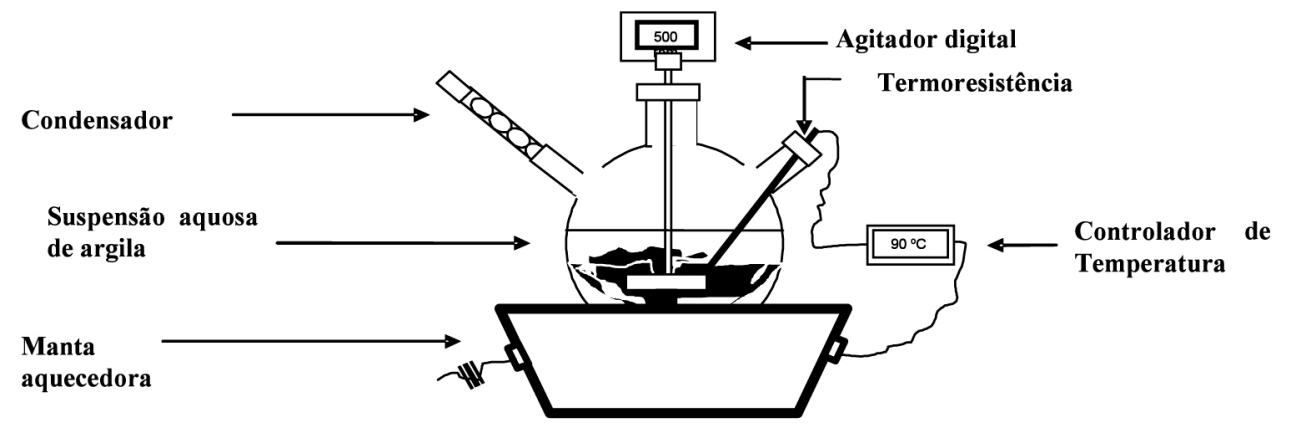

Figura 3: Reator com controle e indicação de temperatura e agitação.

[Figure 3: Reactor with control and indication of temperature and agitation.] 
das argilas in natura e sódica. A Tabela III detalha como foi feita esta parte do experimento.

O reator utilizado para o preparo destes materiais é mostrado na Fig. 3.

Preparação da argila sódica: as argilas in natura foram secas ao sol, destorroadas em britador de mandíbulas Massco Crusher 4 x 6 D 1320, moídas em um moinho de disco Renard MDA-200, separadas em peneiras ABNT 200 (abertura $0,075 \mathrm{~mm}$ ) e calcinadas a $300{ }^{\circ} \mathrm{C}$ durante $48 \mathrm{~h}$. Foram preparadas dispersões contendo $50 \mathrm{~g}$ de argila in natura seca a $300{ }^{\circ} \mathrm{C}, 500 \mathrm{~mL}$ de água deionizada e uma solução de carbonato de sódio, com concentrações do cátion sódio iguais às descritas pelas Tabelas I e II, no reator mostrado na Fig. 3. Decorrido o tempo de contato previamente estabelecido no planejamento experimental, as amostras foram filtradas a vácuo e postas para secar a $100^{\circ} \mathrm{C}$ em uma estufa com circulação forçada de ar. Em seguida as amostras foram destorroadas com auxílio de um almofariz e pistilo e separadas com peneiras ABNT. Foram preparadas dispersões aquosas desses materiais destorroados e em seguida fez-se as leituras das viscosidades plásticas dessas lamas, seguindo as recomendações das normas N-2604 e N-2605 da Petrobrás.

Preparação da argila organofílica: a argila sódica que apresentou o maior valor da viscosidade plástica foi submetida ao ataque com sal quaternário de amônio, bem como sua versão original in natura. Foram postos no reator uma massa igual a $32 \mathrm{~g}$ de argila in natura para o experimento I, $32 \mathrm{~g}$ de argila sódica para os experimentos II e III. Em cada experimento utilizou-se $768 \mathrm{~mL}$ de água deionizada e uma quantidade de sal quaternário de amônio suficiente para preencher $100 \%$ da CTC das argilas in natura e sódica (experimentos I e II) e $150 \%$ da CTC da argila sódica (experimento III). O sal quaternário de amônio utilizado será o cloreto de hexa-decil-tri-metil-amônio. A temperatura do experimento foi $27{ }^{\circ} \mathrm{C}$ e o tempo de contato $2 \mathrm{~h}$. Decorrido o tempo necessário para substituição dos cátions inorgânicos pelo amônio quaternário, as três diferentes argilas organofílicas (provenientes dos experimentos I, II e III) foram filtradas à vácuo e secas a $60{ }^{\circ} \mathrm{C}$ na estufa com circulação forçada de ar, durante $72 \mathrm{~h}$. Elas foram destorroadas com almofariz e pistilo e separadas com peneiras ABNT 200. Elas seguiram então para serem testadas como adsorvente de fenol em soluções aquosas.

Caracterização do material adsorvente: para caracterização da argila organofílica, foram realizados três ensaios: capacidade de troca de cátions (CTC), difração de raios X, em um difratômetro Rigaku Ultima, área superficial específica (BET), em equipamento Micromeritics ASAP 2010.

Estudos de equlíbrio adsortivo: em todos os experimentos relacionados ao processo adsortivo, a metodologia empregada para as análises de fenol na fase líquida foi a cromatografia líquida de alta performance, em um HPLC Shimadzu LC-20A, Prominence, com detector UV $(\lambda=$ $270 \mathrm{~nm}$ ), utilizando-se uma coluna C-18 Shim-Pack ( $5 \mu \mathrm{m}$, 150 x $\phi 4,6$ mm) CLC-ODS (M) e fase móvel água $60 \%$ e metanol $40 \%$.
Escolha do material adsorvente: para os experimentos de equilíbrio, o tempo de contato foi igual $24 \mathrm{~h}$, para que fosse garantida esta condição. A mesa agitadora operou com uma rotação igual a 250 RPM. A separação da solução residual fenólica com argila foi realizada através de filtração comum, sendo avaliada a possibilidade de retenção eventual de moléculas deste adsorvato no filtro, algo que não ocorreu. Foi realizado um estudo de equilíbrio adsortivo para que fosse escolhida a melhor argila organofílica, entre aquelas correspondentes aos experimentos I, II e III. A faixa de concentração de fenol utilizada correspondeu de $20 \mathrm{mg} . \mathrm{L}^{-1}$ a $110 \mathrm{mg} . \mathrm{L}^{-1}$, com volume igual a $100 \mathrm{~mL}$ e massa de argila organofílica igual a $1 \mathrm{~g}$. A argila organofílica que apresentou o melhor resultado no que se refere a menor concentração remanescente de fenol, em solução, no equilíbrio, poderá ser escolhida como material adsorvente, dando continuidade a experimentos futuros.

\section{RESULTADOS E DISCUSSÃO}

\section{Modificação da argila in natura (Síntese das argilas sódicas e organofílicas)}

De acordo com a metodologia descrita, foram obtidos os valores das viscosidades plásticas, das argilas in natura e sódica. As argilas de natureza cálcica da região do AraripePE (São Jorge e Lagoa de Dentro) não permitiram troca por sódio, após a realização do tratamento com carbonato de sódio, de acordo com o planejamento fatorial $2^{3}$, descrito na Tabela I. Essa extrema dificuldade de capacidade de troca catiônica ficou evidenciada pela invariabilidade dos valores da viscosidade plástica da argila in natura tratada com carbonato de sódio. A Tabela IV sumariza os valores das viscosidades plásticas conseguidas pelas argilas do Araripe, PE.

Os valores conseguidos para as viscosidades plásticas das argilas da região do Araripe tratadas com carbonato de sódio, além de serem iguais àqueles apresentados pela argila in natura, estão situados muito abaixo do valor de 4 mPa.s, (Petrobrás norma N-2604) para argilas sódicas, cujas propriedades as recomendam para uso como agente tixotrópico de fluido de perfuração de poços de petróleo base água. A impossibilidade da permuta cálcio (policátions)/ sódio está provavelmente relacionada à tenacidade com que o cálcio é adsorvido pelas esmectitas, devido à rigidez da

Tabela IV - Viscosidades plásticas das argilas do Araripe, PE, antes e após tratamento com carbonato de sódio.

[Table IV - Plastic viscosity Araripe's clay (PE), before and after treatment with sodium carbonate.]

\begin{tabular}{ccc}
\hline \multirow{2}{*}{$\begin{array}{c}\text { ARGILAS DA REGIÃO } \\
\text { DO ARARIPE-PE }\end{array}$} & \multicolumn{2}{c}{$\begin{array}{c}\text { VISCOSIDADE PLÁSTICA } \\
\text { (mPa.s) }\end{array}$} \\
\cline { 2 - 3 } & $\begin{array}{c}\text { Argila in } \\
\text { natura }\end{array}$ & $\begin{array}{c}\text { Argila tratada } \\
\text { com sódio }\end{array}$ \\
\hline São Jorge & 2,0 & 2,0 \\
Lagoa de Dentro & 2,0 & 2,0 \\
\hline
\end{tabular}


Tabela V - Valores das viscosidades plásticas das argilas in natura e sódicas de Boa Vista, PB, conseguidas com base no planejamento experimental estruturado na Tabela I.

[Table V-Plastic viscosities values on natural and sodium clays of Boa Vista, PB, achieved on the basis of experimental structured design in the Table I.]

\begin{tabular}{cccc}
\hline & \multicolumn{3}{c}{$\begin{array}{c}\text { VISCOSIDADE PLÁSTICA } \\
\text { (mPa.s) }\end{array}$} \\
\cline { 2 - 4 } EXPERIMENTO & Verde-Lodo & Chocolate & Bofe \\
\hline In natur $a$ & 2,0 & 2,5 & 2,5 \\
$\mathrm{~T}_{1} \mathrm{t}_{1} \mathrm{C}_{1}$ & 2,0 & 4,0 & 3,0 \\
$\mathrm{~T}_{1} \mathrm{t}_{1} \mathrm{C}_{2}$ & 2,0 & 3,0 & 3,0 \\
$\mathrm{~T}_{1} \mathrm{t}_{2} \mathrm{C}_{1}$ & 2,0 & 3,0 & 3,0 \\
$\mathrm{~T}_{1} \mathrm{t}_{2} \mathrm{C}_{2}$ & 2,0 & 3,5 & 3,0 \\
$\mathrm{~T}_{2} \mathrm{t}_{1} \mathrm{C}_{1}$ & 2,0 & 3,0 & 3,0 \\
$\mathrm{~T}_{2} \mathrm{t}_{1} \mathrm{C}_{2}$ & 2,0 & 3,0 & 3,0 \\
$\mathrm{~T}_{2} \mathrm{t}_{2} \mathrm{C}_{1}$ & 2,5 & 3,5 & 3,5 \\
$\mathrm{~T}_{2} \mathrm{t}_{2} \mathrm{C}_{2}$ & 2,0 & 3,0 & 3,5 \\
\hline
\end{tabular}

camada de água adsorvida por esse cátion. Outra dificuldade de troca relaciona-se à posição particularmente assumida pelo cálcio em relação à estrutura cristalina do argilomineral, quando eventualmente esse cátion, devido à semelhança dimensional do seu diâmetro iônico e os dos vazios existentes na rede cristalina do argilomineral, se encaixa nesses espaços. Em sendo assim, as argilas do Araripe-PE, foram descartadas da condição de matriz para a obtenção da argila organofílica. Das argilas de Boa Vista, a Verde Lodo revelou comportamento semelhante ao observado com as argilas do Araripe, diferindo, apenas, quanto ao valor da viscosidade proporcionada pelo tratamento $\mathrm{T}_{2}, \mathrm{t}_{2}, \mathrm{C}_{1}$, conforme pode ser visto na Tabela V. As argilas Chocolate e Bofe apresentaram valores de viscosidade plástica mais expressivos do que os verificados nos experimentos realizados com a argila Verde Lodo. Em aproximadamente $63 \%$ dos experimentos,

Tabela VI - Viscosidades plásticas da argila Chocolate. [Table VI - Plastic viscosity of Chocolate clay.]

\begin{tabular}{ccc}
\hline & \multicolumn{2}{c}{$\begin{array}{c}\text { VISCOSIDADE PLÁSTICA } \\
\text { (mPa.s) }\end{array}$} \\
\cline { 2 - 3 } EXPERIMENTO & $\begin{array}{c}\text { Inicial } \\
\text { (Tabela V) }\end{array}$ & Repetição \\
\hline $\mathrm{T}_{1} \mathrm{t}_{1} \mathrm{C}_{1}$ & 4,0 & 4,0 \\
$\mathrm{~T}_{1} \mathrm{t}_{1} \mathrm{C}_{2}$ & 3,0 & 3,5 \\
$\mathrm{~T}_{1} \mathrm{t}_{2} \mathrm{C}_{1}$ & 3,0 & 3,5 \\
$\mathrm{~T}_{1} \mathrm{t}_{2} \mathrm{C}_{2}$ & 3,5 & 3,5 \\
$\mathrm{~T}_{2} \mathrm{t}_{1} \mathrm{C}_{1}$ & 3,0 & 3,5 \\
$\mathrm{~T}_{2} \mathrm{t}_{1} \mathrm{C}_{2}$ & 3,0 & 3,0 \\
$\mathrm{~T}_{2} \mathrm{t}_{2} \mathrm{C}_{1}$ & 3,5 & 3,0 \\
$\mathrm{~T}_{2} \mathrm{t}_{2} \mathrm{C}_{2}$ & 3,0 & 3,0 \\
Médio $\left(\mathrm{T}_{\mathrm{m}} \mathrm{t}_{\mathrm{m}} \mathrm{C}_{\mathrm{m}}\right)$ & 3,0 & 3,0 \\
\hline
\end{tabular}

Tabela VII - Viscosidades plásticas da argila Chocolate com níveis dos fatores minimizados.

[Table VII - Plastic Viscosity of Chocolate clay with reduced levels of factors.]

VISCOSIDADE PLÁSTICA (mPa.s)

\begin{tabular}{ccc}
\cline { 2 - 3 } EXPERIMENTO & Chocolate & $\begin{array}{c}\text { Chocolate } \\
\text { Repetição }\end{array}$ \\
\hline $\mathrm{T}_{1}, \mathrm{t}_{1}, \mathrm{C}_{1}$ & 4,0 & 4,0 \\
$\mathrm{~T}_{1}, \mathrm{t}_{1}, \mathrm{C}_{0}$ & 2,5 & 2,5 \\
$\mathrm{~T}_{1}, \mathrm{t}_{0}, \mathrm{C}_{1}$ & 3,5 & 3,5 \\
$\mathrm{~T}_{1}, \mathrm{t}_{0}, \mathrm{C}_{0}$ & 2,5 & 2,5 \\
$\mathrm{~T}_{0}, \mathrm{t}_{0}, \mathrm{C}_{0}$ & 2,5 & 2,5 \\
$\mathrm{~T}_{0}, \mathrm{t}_{0}, \mathrm{C}_{1}$ & 3,0 & 3,5 \\
$\mathrm{~T}_{0}, \mathrm{t}_{1}, \mathrm{C}_{0}$ & 2,5 & 2,5 \\
$\mathrm{~T}_{0}, \mathrm{t}_{1}, \mathrm{C}_{1}$ & 3,0 & 3,5 \\
Médio $\left(\mathrm{T}_{\mathrm{m}}, \mathrm{t}_{\mathrm{m}}, \mathrm{C}_{\mathrm{m}}\right)$ & 3,0 & 2,5 \\
\hline
\end{tabular}

as viscosidades plásticas das argilas Chocolate e Bofe apresentaram coincidência de valores, em todos os casos abaixo de $4 \mathrm{mPa}$.s. $\mathrm{O}$ maior valor de viscosidade plástica conseguido com a argila Bofe (3,5 mPa.s), foi obtido a partir do experimento em que os maiores níveis dos fatores $\left(\mathrm{T}_{2}, \mathrm{t}_{2}, \mathrm{C}_{2}\right)$ foram considerados. A argila Chocolate revelou viscosidade plástica de $4 \mathrm{mPa}$.s, na condição experimental em que os fatores envolvidos foram considerados com os seus menores níveis $\left(T_{1}, t_{1}, C_{1}\right)$, como pode ser verificado na Tabela V.

O estudo das repetições autênticas dos experimentos, realizado para a argila Chocolate, demonstrou que ocorreram variações dos valores das respostas (viscosidade plástica) em 44,4\%, comparando-se os valores obtidos inicialmente com os valores obtidos pelas repetições. A magnitude dessas variações pode ser desprezada devido à imprecisão de leitura na medição da viscosidade no viscosímetro Fann 35A. A Tabela VI indica os valores das viscosidades plásticas da argila Chocolate, nas condições iniciais (Tabela V), e da repetição dos experimentos.

A resposta da viscosidade plástica da argila Chocolate, após a repetição dos experimentos, demonstrou que a condição experimental $\left(\mathrm{T}_{1}, \mathrm{t}_{1}, \mathrm{C}_{1}\right)$ reproduziu propriedades tixotrópicas na argila tratada equivalente à conseguida no planejamento inicial, atestadas pela viscosidade plástica de 4 mPa.s. Houve a necessidade de realizar outro planejamento fatorial $2^{3}$, descrito pela Tabela II, devido à condição de tixotropia da argila Chocolate ter sido conseguida com os menores níveis dos fatores do planejamento fatorial descrito pela Tabela I. Para realização desta etapa, diminuíram-se os níveis de temperatura, tempo de contato e concentração de sódio $\left(\mathrm{T}_{0}, \mathrm{t}_{0}, \mathrm{C}_{0}\right)$. Os resultados das viscosidades plásticas para este novo planejamento estão descritos na Tabela VII.

Considerando estas premissas, foi admitido que a condição experimental $\mathrm{T}_{1} \mathrm{t}_{1} \mathrm{C}_{1}\left(4{ }^{\circ} \mathrm{C}, 3 \mathrm{~h}\right.$ e 100 meq de sódio), que proporcionou viscosidade de $4 \mathrm{mPa} . \mathrm{s}$ na 
argila Chocolate, confirmada na repetição autêntica dos experimentos do planejamento inicial e do planejamento com níveis dos fatores minimizados (Tabela VII), poderia representar a condição experimental para replicar satisfatoriamente a argila sódica a ser utilizada na produção da argila organofílica. Para a produção da argila organofílica, a argila escolhida obviamente pelos valores da viscosidade plástica, foi a argila Chocolate. Foram considerados os experimentos baseados na metodologia descrita pela Tabela III.

\section{Caracterização dos materiais}

A capacidade de troca de cátions representa o somatório de todos os cátions contidos nas regiões intercamadas do argilomineral. Os resultados desta análise estão descritos na Tabela VIII.

A troca de cálcio e magnésio por sódio, na argila Chocolate, foi extremamente bem sucedida. Isto implica numa troca bem mais efetiva com o sal quaternário de amônio uma vez que a argila tratada com sódio é mais suscetível à hidratação.

Os resultados da difração de raios $\mathrm{X}$ para as argilas in natura seca a $300{ }^{\circ} \mathrm{C}$ e hidratada, e sódica seca a $100{ }^{\circ} \mathrm{C}$ e hidratada estão mostrados na Fig. 4.

Os resultados da difração de raios $\mathrm{X}$ para a argila organofílica antes e após sua utilização como material adsorvente na remoção do fenol estão na Fig. 5 .

Os espaçamentos intercamadas (nm), para as argilas in natura seca a $300{ }^{\circ} \mathrm{C}$ e hidratada, sódica seca a $100{ }^{\circ} \mathrm{C}$ e hidratada e organofílica antes e após a adsorção do fenol estão na Tabela IX.

Os resultados das análises por difração de raios $\mathrm{X}$ mostraram um aumento no espaçamento basal da argila organofílica em relação aos espaçamentos basais das argilas in natura e sódica. Também mostraram um leve aumento no pico da argila organofílica após adsorção do fenol quando comparada com a mesma antes da adsorção. O fato da difração de raios $\mathrm{X}$ da argila sódica ter revelado um pico de $1,260 \mathrm{~nm}$ está relacionado à secagem realizada após tratamento por sódio. Comparando os resultados das amostras in natura e sódica, ambas sem hidratação, não é possível fazer-se uma análise muito precisa sobre o que aconteceu na região intercamadas da argila sódica nas condições em que elas foram analisadas (por DRX). Isto acontece porque a amostra sódica foi submetida a uma secagem à temperatura de $100^{\circ} \mathrm{C}$ por um tempo longo para permitir o peneiramento. Isto provoca uma desidratação da região intercamadas, que é tanto mais severa quanto maior for o tempo de secagem [2]. A melhor forma de comparar a eficiência da troca iônica cálcio/sódio corresponde àquela em que se faz um tratamento com água. Neste caso, colocaram-se as duas argilas (in natura e sódica) em condições equivalentes de hidratação e a diferença de comportamento adsortivo entre elas fica evidente. É o que pôde ser visto por comparação entre os DRX das amostras in natura e sódica hidratadas, verificado na Fig. 4, e ratificado pelos resultados da Tabela IX. O maior inchamento da argila sódica tratada com água evidencia que houve uma troca cálcio/sódio eficiente. Ou seja, muito cálcio foi trocado por sódio, como ficou visto nos resultados da CTC. A água presente na região intercamadas, notadamente pelo fato de estar associada ao sódio, facilita a posterior troca por sal quaternário. Os cátions adsorvidos podem se tornar hidratados e se encontrar na forma de íons complexos com água coordenada. No caso do íon cálcio, essa água coordenada ao íon tem uma configuração geométrica octaédrica bem definida e influencia as moléculas de água que se acham próximas. Assim, os íons cálcio diminuem a espessura da camada de água adsorvida pela sua maior carga e pequeno raio iônico, dando-lhe uma configuração geométrica bem definida. O íon sódio de igual raio iônico e menor carga, com hidratação "frouxa", permite que a camada de água tenha uma maior espessura a um menor grau de orientação [2].

Foi realizado o ensaio de inchamento Foster com a argila Chocolate in natura e sódica. O ensaio de Foster baseia-se no grau de hidratação da argila e é realizado colocando-se $1 \mathrm{~g}$ de argila em uma proveta de $100 \mathrm{~mL}$ contendo $50 \mathrm{~mL}$ de água deionizada. Após $24 \mathrm{~h}$ em repouso é feita a leitura do inchamento em $\mathrm{mL} \cdot \mathrm{g}^{-1}$. Valores iguais ou inferiores a $2 \mathrm{~mL} \cdot \mathrm{g}^{-1}$ são considerados como não inchamento, de $3 \mathrm{a}$ $5 \mathrm{~mL} \cdot \mathrm{g}^{-1}$ como inchamento baixo, de 6 a $8 \mathrm{~mL}^{-1} \mathrm{~g}^{-1}$ como

Tabela VIII - CTC das argilas in natura e chocolate sódica (meq.100 g $\left.\mathrm{g}^{-1}\right)$.

[Table VIII - CEC of natural clays and sodium chocolate (meq.100 $\left.\mathrm{g}^{-1}\right)$.]

\begin{tabular}{ccccccccc}
\hline \multirow{2}{*}{ Amostras } & \multicolumn{9}{c}{ Cátions Trocáveis } \\
& $\mathrm{Ca} 2+$ & $\mathrm{Mg} 2+$ & $\mathrm{Na}+$ & $\mathrm{K}+$ & $\mathrm{Al}+$ & $\mathrm{H}+$ & $\mathrm{CTC}$ & $\mathrm{pH}$ \\
\hline Lagoa de & 67,50 & 12,80 & 5,60 & 1,60 & 0,00 & - & 87,5 & 7,10 \\
Dentro & & 13,65 & 1,40 & 0,64 & 0,00 & - & 37,44 & 7,60 \\
São Jorge & 21,75 & 19,65 & 6,40 & 0,62 & 0,00 & 1,56 & 35,6 & 6,00 \\
Verde Lodo & 7,40 & 17,40 & 6,60 & 0,28 & 0,00 & 2,39 & 31,8 & 5,60 \\
$\quad$ Bofe & 5,15 & 36,20 & 13,13 & 0,55 & 0,10 & 3,78 & 71,31 & 5,90 \\
$\begin{array}{c}\text { Chocolate } \\
\text { In Natura }\end{array}$ & 17,55 & & & & & & & \\
Chocolate & 1,60 & 2,35 & 74,74 & 0,55 & 0,00 & 0,00 & 79,34 & 10,10 \\
$\quad$ Sódica & & & & & & & &
\end{tabular}




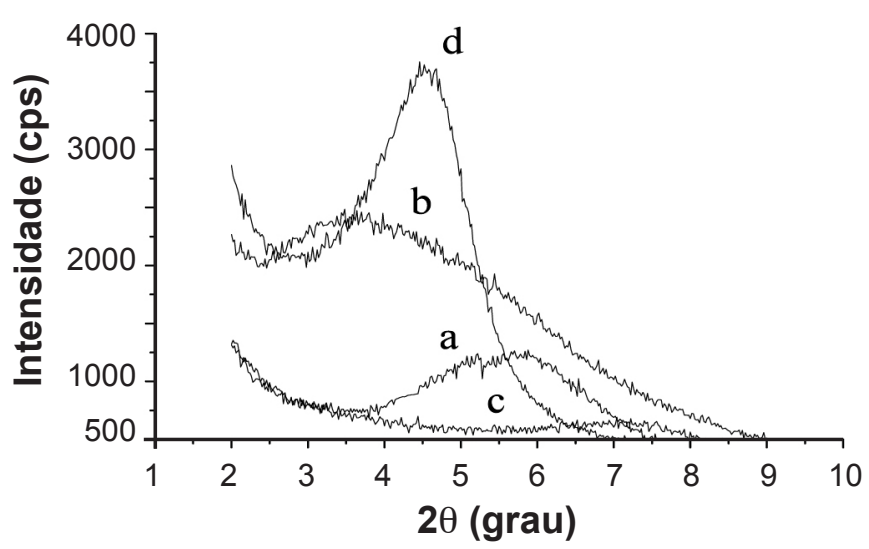

Figura 4: Difratogramas de raios X das argilas in natura seca (a) e hidratada (b); sódica seca (c) e hidratada (d).

[Figure 4: X-ray diffraction patterns of in nature dry clay (a) and hydrated (b) dry sodium (c) and hydrated (d).]

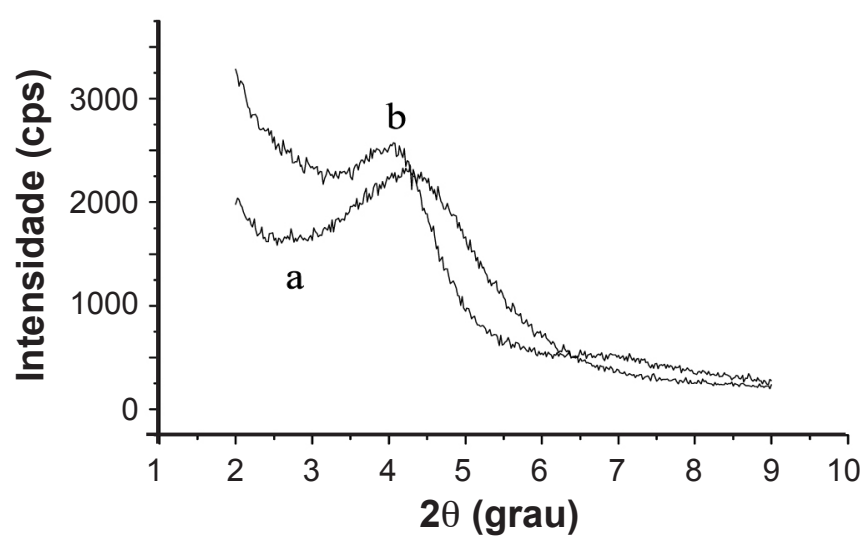

Figura 5: Difratogramas de raios $\mathrm{X}$ da argila organofílica antes da adsorção (a) e a mesma após adsorção do fenol (b).

[Figure 5: X-ray diffraction patterns of organophilic clays before the adsorption ( $a$ ) and after the adsorption of phenol ( $b$ ).]

inchamento médio e acima de $8 \mathrm{~mL} \cdot \mathrm{g}^{-1}$ como inchamento alto [24]. A argila Chocolate in natura mostrou inchamento de $4 \mathrm{~mL} \cdot \mathrm{g}^{-1}$, enquanto que a sódica revelou inchamento de 15 $\mathrm{mL} . \mathrm{g}^{-1}$. A área superficial total, que representa a soma entre a área da superfície externa e a área dos poros do material adsorvente, apresentou um valor igual a $88,70 \mathrm{~m}^{2} \cdot \mathrm{g}^{-1}$ para a argila organofílica, após a análise de BET.

Estudo adsortivo para determinação do material adsorvente

Os resultados do processo adsortivo estão representados nas Figs. 6 e 7. Na Fig. 6, os pontos experimentais têm como base a isoterma de Langmuir-Freundlich, descrita pela equação C, enquanto que a Fig. 7 tem como referência esta mesma isoterma, porém na sua forma linearizada, como mostra a equação D. Foram determinados $K_{A}$ e $Q^{S A T}$ pelos coeficientes lineares e angulares das retas formadas.

A Fig. 6 indica que a argila que melhor adsorveu o fenol foi organofílica III, resultante da versão sódica tratada com excesso de SQA (150\% da CTC). Este resultado converge
Tabela IX - Espaçamentos intercamadas das formas in natura seca e hidratada, sódica seca e hidratada e organofílica antes e após adsorção do fenol, da argila Chocolate, Boa Vista, PB.

[Table IX - Interlayer spacing of hydrated and dry forms by natural Chocolate clay, dry and hydrated sodium and organophilic Chocolate clay, before and after adsorption of phenol, Boa Vista, PB.]

\begin{tabular}{cc}
\hline TIPO DE ARGILA & $\begin{array}{c}\text { ESPAÇAMENTO BASAL } \\
(\mathrm{nm})\end{array}$ \\
\hline In natura & 1,549 \\
In natura Hidratada & 1,963 \\
Sódica Seca & 1,260 \\
Sódica Hidratada & 2,454 \\
Organofílica & 2,092 \\
Organofílica após & 2,102 \\
adsorção & \\
\hline
\end{tabular}

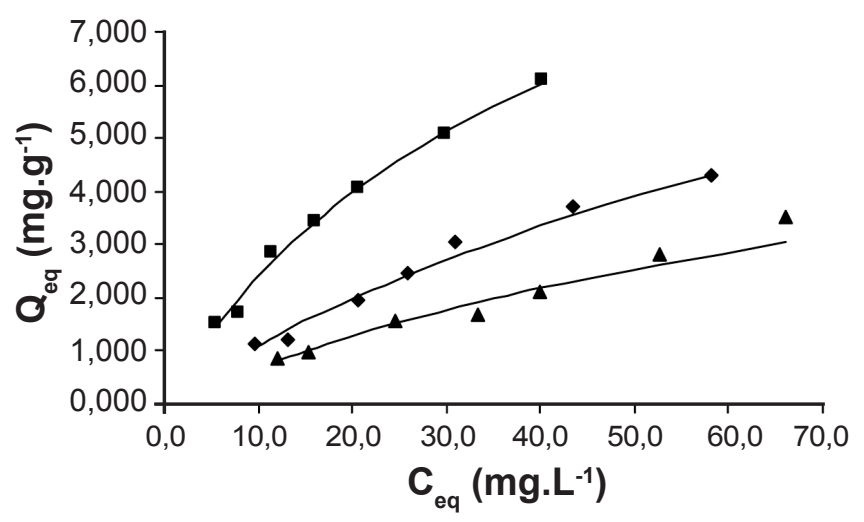

Figura 6: Curvas de equilíbrio para diferentes tipos de argila organofílica, provenientes dos experimentos I $(\boldsymbol{A})$, II $(\bullet)$ e III ( $\mathbf{\square})$. $\mathrm{T}=27^{\circ} \mathrm{C}, \mathrm{m}=1 \mathrm{~g} \mathrm{e} \mathrm{V}=100 \mathrm{~mL}$.

[Figure 6: Equilibrium curves of different types of organophilic clay, from the experiments $I(\mathbf{\Delta}), I I(\bullet)$ and III ( $\mathbf{\square}) . T=27^{\circ} \mathrm{C}, \mathrm{m}$ $=1 \mathrm{~g}$ and $\mathrm{V}=100 \mathrm{~mL}$.]

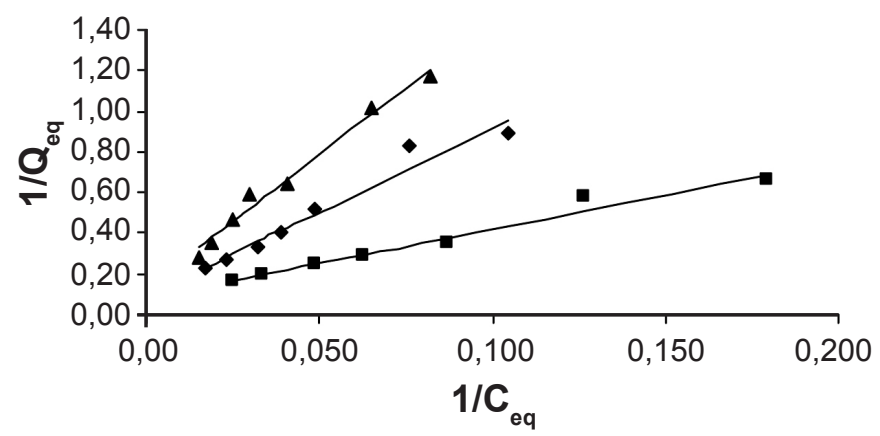

Figura 7: Curvas de equilíbrio linearizada para diferentes tipos de argila organofílica, provenientes dos experimentos I $(\mathbf{A})$, II $(\diamond)$ e III (ם). T $=27^{\circ} \mathrm{C}, \mathrm{m}=1 \mathrm{~g} \mathrm{e} \mathrm{V}=100 \mathrm{~mL}$.

[Figure 7: Linearization curves balance for different types of organophilic clay, from the experiments $I(\mathbf{\Delta}), I I(\bullet)$ and III (ם). $T=27^{\circ} \mathrm{C}, \mathrm{m}=1 \mathrm{~g}$ and $\mathrm{V}=100 \mathrm{~mL}$.] 
Tabela X - Capacidade máxima adsortiva e constante de equilíbrio para diferentes argilas organofílicas. [Table X - Maximum adsorptive capacity and equilibrium constant for different clay organophilic.]

\begin{tabular}{cccc} 
Argila Organofílica & $\begin{array}{c}\text { Coeficiente de } \\
\text { Regressão Linear }\end{array}$ & $\begin{array}{c}\text { Capacidade Máxima } \\
\text { Adsortiva } \\
\mathrm{Q}_{\mathrm{A}}^{\text {SAT }}\left(\mathrm{mg} \cdot \mathrm{g}^{-1}\right)\end{array}$ & $\begin{array}{c}\text { Constante de Equilíbrio } \\
\mathrm{K}_{\mathrm{A}}\left(\mathrm{L}^{\left.-\mathrm{mg}^{-1}\right)}\right.\end{array}$ \\
\hline I & $0,9850 \pm 0,0059$ & $7,648 \pm 0,102$ & $0,010 \pm 0,001$ \\
II & $0,9582 \pm 0,0092$ & $11,004 \pm 0,097$ & $0,011 \pm 0,001$ \\
III & $0,9721 \pm 0,0062$ & $12,287 \pm 0,092$ & $0,024 \pm 0,001$ \\
\hline
\end{tabular}

para a consequiência do uso em excesso de SQA em tratamentos que objetivam obtenção de argilas organofílicas, promovendo adsorção do sal, tanto nas regiões intercamadas, quanto nos sítios ativos superficiais dos argilominerais [6].

A Fig. 7, de acordo com os resultados dos coeficientes de regressão linear mostrados na Tabela $X$, sugere um valor para a intensidade adsortiva próximo a unidade, $n \cong 1$, simplificando o modelo de Langmuir-Freundlich, indicando adsorção em monocamadas. Neste caso o valor da capacidade máxima adsortiva e da constante de equilíbrio independem da massa de adsorvente ou do volume da solução. Os resultados da capacidade máxima adsortiva $\left(Q_{A}{ }_{A}^{\text {SAT }}\right)$ e da constante de equilíbrio adsortivo $\left(K_{A}\right)$ foram determinados ajustando os dados obtidos experimentalmente à equação D. Os valores estão expressos na Tabela X.

De acordo com a Análise de Variância (ANOVA), desenvolvida para avaliar o ajuste do modelo de LangmuirFreundlich aos resultados obtidos experimentalmente, pode-se dizer que o mesmo é adequado, pois o coeficiente de determinação do modelo $\left(D^{2}\right)$ foi igual a 0,9752 para o experimento I, 0,9812 para o experimento II e 0,9789 para o experimento III, sendo portanto nos três casos próximos à unidade.

\section{CONCLUSÕES}

Na sequiência de proposição de um processo de tratamento de um efluente sintético, via remoção de fenol por adsorção com argilas esmectíticas, formulou-se um adsorvente organofílico após modificação catiônica na sua região intercamadas. A preparação deste material e sua posterior aplicação na remoção de fenol de soluções aquosas são base para um conjunto de conclusões: a) as argilas da região do Araripe, PE, não realizaram troca por sódio, devido a rigidez da camada de água adsorvida pelos cátions cálcio, presentes em elevado teor na região intercamadas dessas esmectitas; b) as argilas de Boa Vista, PB, em especial a Bofe e a Chocolate, revelaram boa capacidade de hidratação da região intercamadas, evidenciada pela diferença dimensional do espaçamento basal entre as formas in natura e sódica (raios $\mathrm{X})$ e pelo incremento do valor da viscosidade plástica; c) a argila Chocolate apresentou o maior valor para viscosidade plástica (4 mPa.s), sendo, por isto, escolhida como matriz para a síntese da argila organofílica utilizada como material adsortivo. Foram realizados ensaios adsortivos visando a remoção de fenol por adsorção com argilas organofílicas, com as seguintes conclusões: a) a argila organofílica proveniente do experimento III mostrou-se ser o adsorvente mais eficaz na redução dos teores de fenol quando comparada com as argilas organofílicas provenientes dos experimentos I e II devido ao uso em excesso do sal quaternário de amônio, com remoções superiores a 70\% (para uma relação de massa e volume iguais a $1 \mathrm{~g}$ de argila e $100 \mathrm{~mL}$ de solução); b) a análise estatística mostrou que o modelo de LangmuirFreundlich ajustou-se de forma satisfatória aos dados experimentais para o equilíbrio adsortivo.

\section{AGRADECIMENTOS}

Ao Prof. Mohand Benachour (DEQ, UFPE), que gentilmente cedeu o cromatógrafo HPLC; ao Prof. H. C. Ferreira, UFCG, pelo envio da argila Chocolate; à Clariant do Brasil, pelo fornecimento do sal quaternário de amônio; ao convênio CAPES/FACEPE e ao CNPq (Projeto Universal) pelo suporte financeiro.

\section{REFERÊNCIAS}

[1] Y. E. Nahhal, J. Safi, J. Food, Agric. \& Environ. 3, 2 (2004) 295.

[2] P. S. Santos, Ciência e tecnologia de argilas, $2^{\text {a }}$ Ed., Edgard Blucher, S. Paulo, SP (2002) 195.

[3] M. G. Neumann, F. Gessner, A. P. P. Cione, R. A. Sartori, C. C. Schmitt Cavalheiro, Química Nova 26, 6 (2000) 818. [4] A. R. Zandonadi, P. S. Santos, Cerâmica 25 (1978) 355. [5] R. R. Menezes, M. M. Avila Júnior, L. N. L. Santana, G. A. Neves, H. C. Ferreira, Cerâmica 54 (2008) 152.

[6] K. R. O. Pereira, M. G. F. Rodrigues, F. R. V. Diaz, Eletrônica de Materiais e Processos 2, 2 (2007) 1.

[7] M. G. F. Rodrigues, M. L. Silva, M. G. C. Silva, Cerâmica 50 (2004) 190.

[8] A. F. Almeida Neto, A. A. Silva, F. R. V. Diaz, M. G. F. Rodrigues, VI Encontro Latino Americano de PósGraduação, São José dos Campos, SP (2006) 2410.

[9] J. B. Mariano, Impactos Ambientais do Refino do Petróleo, Diss. Mestrado, COPPE, UFRJ, Rio de Janeiro, RJ (2001).

[10] L. M. Barros Júnior, Petroquímica, Petróleo, Gás \& Química 58 (2004) 62.

[11] CONAMA, Conselho Nacional do Meio Ambiente. 
Resolução 357/2005.

[12] G. Solomons, C. Fryhle, Química Orgânica, $7^{\mathrm{a}}$ Ed., vol. 2, LTC, S. Paulo, SP (2002) 265.

[13] H. Teng, C. To, J. Colloid and Interf. Sci. 230 (2000) 171.

[14] H. Wake, Estuarine Coastal and Shelf Science 62 (2005) 131.

[15] T. V. Otokunefor, C. Obiukwu, Appl. Ecology and Environ. Res. 3, 1 (2005) 61.

[16] S. H. Lin, R. C. Hsiao, R. S. Juang, J. Hazardous Mater. 135 (2005) 134.

[17] M. C. Irene, C. H. Samuel, K. M. Raymond, Waste Management Res. 16 (1998), 129.

[18] A. A. Sameer, F. Banat, L. Abu-Aitah, Separation and
Purification Technology 33 (2003) 1.

[19] N. Yilmaz, S. Yapar, Appl. Clay Sci. 27 (2004) 223.

[20] M. Akçay, J. Colloid Interf. Sci. 296 (2005) 16.

[21] Monique A. M. Lawrence, R. K. Kukkadapu, S. A. Boyd, Appl. Clay Sci. 13 (1998) 13.

[22] S. E. Burns, S. L. Bartelt-Hunt, J. Smith, J. Hazardous Mater. 96, (2003) 91.

[23] B. Barros Neto, I. S. Scarminio, R. E. Bruns, Como Fazer Experimentos, $2^{\mathrm{a}}$ Ed., Editora Unicamp, Campinas, SP (2002) 214.

[24] F. R. V. Diaz, "Obtenção, a nível de laboratório, de algumas argilas esmectíticas organofílicas", Tese Dr., Departamento de Engenharia Química, USP, S. Paulo, SP (1994).

(Rec. 17/03/2009, Ac. 06/06/2009) 